\title{
FORMAÇÃO DE PROFESSORES E EDUCADORES PARA ABORDAGEM DA EDUCAÇÃO SEXUAL NA ESCOLA: O QUE MOSTRAM AS PESQUISAS*
}

\section{Background of teachers and educators for approach to sexual education at schools: what research works show}

\author{
Regina Célia Pinheiro da Silva ${ }^{1}$ \\ Jorge Megid Neto ${ }^{2}$
}

\begin{abstract}
Resumo: Este artigo estuda as produções de pós-graduação brasileiras sobre formação de professores/educadores para o trabalho com Educação Sexual nos vários níveis escolares, com objetivo de conhecer e apontar as principais tendências dessa produção. A metodologia baseou-se na pesquisa do estado da arte, identificando 65 teses e dissertações que são descritas e analisadas, entre outros itens, quanto aos modelos de formação inicial e continuada, características e concepções/representações dos profissionais, elementos teóricos, históricos e curriculares tratados nas pesquisas. Resultados apontam profissionais despreparado,s tanto na formação inicial quanto na continuada.
\end{abstract}

Palavras-chave: educação sexual. formação inicial e continuada de professores/educadores. estado da arte.

\begin{abstract}
This paper deals with Brazilian postgraduate research outcomes on teachers and educators training to approach sexual education at school, aiming to know and point out its main tendencies. The methodology used in the study was the state of the art research, through the identification of 65 thesis and master degrees' dissertations which are described and analyzed, according to initial and continuous teacher's forming models; professional's features and conceptions/representations; theoretical, historical and curricular elements studied in these researches. Research outcomes show unprepared professionals in term of initial formation as well as continuous schooling.
\end{abstract}

Keywords: sexual education. teachers' and educators' initial and continuous schooling. state of art.

\footnotetext{
* Este artigo tem base na dissertação de mestrado "Pesquisas sobre formação de professores/educadores para abordagem da Educação Sexual na escola", defendida em fevereiro de 2004 na Faculdade de Educaşão da Universidade Estadual de Campinas, Unicamp, Campinas, SP, por Regina Célia Pinheiro da Silva.

${ }^{1}$ Professora Assistente Mestre do Departamento de Serviço Social da Universidade de Taubaté, UNITAU, Taubaté, SP. E-mail: reginacps@superig.com.br

${ }^{2}$ Professor Doutor da Faculdade de Educação da Unicamp. E-mail: megid@unicamp.br
} 


\section{Introdução}

As normas e os comportamentos ligados à sexualidade, no contexto histórico, social e cultural, sempre foram norteados por valores e princípios religiosos e, posteriormente, ligados à fertilidade e às relações de convivência que iam sendo estabelecidas pelos grupos sociais (Shiavo e Silva, 1997).

A Educação Sexual de crianças e de jovens sempre existiu, mas se fez mais pela omissão e repressão do que por intermédio de uma educação dialogal, humanista e libertária. A família, desde o nascimento da criança, incute o que é permitido ou não em matéria de sexualidade, nem sempre de forma verbalizada. $\mathrm{Na}$ escola, os professores repassam consciente ou inconscientemente noções sobre Sexualidade e Educação Sexual, por meio de verbalizações e/ou posturas, noções essas que recebem reforço dos meios de comunicação, podendo ser positivas e instrutivas ou repressoras e castradoras.

No Brasil, a preocupação com o tema inicia-se no final dos anos 1920 e década de 1930, pautada no estímulo ao medo das "doenças venéreas" e, por conseguinte, na repressão à sexualidade (Sayão, 1997). As primeiras experiências formais e sistematizadas de Educação Sexual nas escolas acontecem nos anos 1960, nos estados do Rio de Janeiro, São Paulo e Belo Horizonte, e são extintas após o início dos governos militares.

Em 1971, a Lei 5692/71 altera as Diretrizes e Bases da Educação Brasileira e institui o Ensino de $1^{\circ}$ e $2^{\circ}$ graus. Torna obrigatória a inclusão de Programas de Saúde no currículo escolar, favorecendo que as escolas passem a tratar de questões ligadas à sexualidade humana, o que não era oficialmente permitido.

Bagnato menciona que, em 1974, o Parecer 2.264, do Conselho Federal de Educação recomenda que os Programas de Saúde sejam planejados de acordo com as necessidades do meio e do aluno, devendo ser estabelecidos em conjunto por representantes dos órgãos de saúde, docentes e universidades locais, visando "a auto-capacitação dos indivíduos e da sociedade para lidar com problemas fundamentais do cotidiano, como o desenvolvimento biopsicológico, nutrição, reprodução, etc." (Bagnato, 1987, p. 18).

De modo contraditório, em 1978, um documento do então Ministério da Educação e Cultura (MEC) manifesta-se contrariamente à Educação Sexual no espaço escolar. Somente em 1992, a partir de preocupações com o crescente aumento da aids, a Portaria Interministerial $n^{\circ} 796$ propõe a implantação, manutenção e/ou ampliação de projeto educativo de prevenção à aids nas redes oficiais e privadas de ensino em todos os níveis, o que é iniciado nos anos seguintes. No entanto, fica claro que a preocupação não é com a Educação Sexual em si, mas com a epidemiologia da doença.

Nesse movimento, a proposta de inclusão da Educação Sexual nas escolas de todo o país retoma com grande intensidade a partir da publicação dos Parâmetros Curriculares Nacionais (PCNs), cujo caderno sobre "Pluralidade Cultural e Orientação Sexual", publicado em 1997, apresenta a política do governo federal para a área.

O documento introdutório dos PCNs aponta que "a proposta (...) para Orientação Sexual é que a escola trate da sexualidade como algo fundamental na vida das pessoas" (Brasil, 1998, p. 67). A intervenção pedagógica deve ser não-diretiva em relação ao comportamento dos alunos, buscando informar e problematizar questões da sexualidade, ressaltando o trabalho a partir das posturas, das crenças, dos tabus e dos valores a ela associados, o que garante o espaço de 
Formação de professores e educadores...

formação dos educandos e não apenas a veiculação de informações. Prevê que o professor prepare-se para a intervenção prática mediante leituras e discussões e tenha um espaço grupal de supervisão continuada e sistemática que possibilite uma reflexão sobre essa prática e sobre seus próprios valores e limites, o que o ajudará a ampliar sua consciência em relação à sexualidade e à visão de mundo, além de assumir uma postura ética na sua atuação.

Por outro lado, a não obrigatoriedade dos PCNs (Lüdke, 2000), associada à tendência ao conservadorismo e à estagnação a que a escola está sujeita, como qualquer outra instituição social, torna possível que a implantação da Educação Sexual continue restrita apenas a algumas experiências isoladas.

\section{Procedimentos metodológicos}

A pesquisa buscou conhecer as características e tendências das pesquisas de pósgraduação (dissertações e teses) que tratam da formação dos professores e educadores para atuarem com Educação Sexual no espaço escolar. Assim, identificar, descrever, analisar e sistematizar as tendências dessa produção acadêmica constituiu o principal objetivo deste trabalho.

Foram incluídos como educadores, além dos professores, os profissionais da área da saúde - desde que tenham lidado com a Educação Sexual no espaço escolar, ou que, na sua formação inicial no nível superior ou no Ensino Médio, tenham sido preparados para essa abordagem. Sabe-se que, com freqüência, tais profissionais são convidados a ir à escola para palestras, seminários e debates numa ação informativa dentro do processo de Educação Sexual, ou ainda participam de cursos e treinamentos desenvolvendo ações pedagógicas que visam à formação de professores.

A metodologia utilizada foi a pesquisa do tipo "estado da arte", que inventaria, sistematiza e avalia a produção em determinada área do conhecimento e num período previamente estabelecido (Megid Neto, 1999). Possui característica quali-quantitativa em que a análise qualitativa dos dados quantitativos busca "uma sintese unificadora do conbecimento" (Baptista, 1999, p.34). Para Gamboa (1987), esse tipo de pesquisa dá maior visibilidade à produção, permite uma reflexão crítica sobre a mesma e facilita o acesso e a utilização das experiências realizadas.

Numa primeira etapa, a revisão bibliográfica abrangeu todas as produções de pósgraduação que tratavam sobre Educação Sexual nas escolas. O primeiro instrumento utilizado para identificação dos documentos foi o catálogo do Centro de Documentação em Ensino de Ciências (CEDOC) da Faculdade de Educação da Unicamp: "O ensino de Ciências no Brasil: catálogo analítico de teses e dissertações: 1972-1995” (Megid Neto, 1998). Também foram utilizados outros catálogos complementares do CEDOC, incluindo uma atualização preliminar do catálogo já citado referente ao período de 1996-2001.

O levantamento de dados também foi efetuado em sites de diversas instituições de ensino superior (IES) ou em bancos de dados, tais como os do: IBICT (Instituto Brasileiro de Informação em Ciência e Tecnologia); da CAPES (Coordenação de Aperfeiçoamento de Pessoal de Nível Superior); e o CD-Rom da ANPEd (Associação Nacional de Pós-Graduação e Pesquisa em Educação).

Boa parte da pesquisa foi consumida nessa fase de busca das referências bibliográfi- 
cas, dos resumos das teses e dissertações e com a verificação se os documentos referiam-se ao contexto escolar. Em muitos resumos foi constatada falta de informações básicas para os propósitos de seleção, dificultando a inclusão imediata das respectivas pesquisas entre os documentos selecionados e demandando vários procedimentos para uma melhor avaliação.

A busca de informações sobre dissertações e teses foi realizada a partir dos anos 1970, quando se iniciam as primeiras defesas nos programas de pós-graduação em Educação no Brasil. Foram utilizados, nesse processo, os seguintes termos como palavras-chave para a busca: educação sexual; orientação sexual; sexo na escola; sexualidade na escola. Foram identificados 165 documentos que se referem de forma ampla à Educação Sexual nas escolas, compreendidos entre 1977 (ano em que foi identificada a primeira produção sobre o tema) e 2001. Todos os resumos desses trabalhos foram obtidos e, a partir da leitura dos resumos, foram selecionadas 65 dissertações e teses (cerca de 40\% do conjunto das 165 produções), que tratam da formação do professor/educador.

O procedimento seguinte foi a definição dos descritores a partir dos quais as produções foram classificadas e descritas. Como em Megid Neto (1999) e Fracalanza (1993), foi utilizado o termo descritor para indicar os aspectos observados na classificação e descrição das teses e dissertações, bem como na análise de suas características e tendências. Eles foram estabelecidos partindo, na sua seleção inicial, da leitura da tese de doutorado de Megid Neto (1999) e das dissertações de mestrado de Verardo (1989), Ribeiro (1989), Fruet (1995), Schussel (1982) e Figueiró (1996). A partir dos 65 resumos, fez-se uma seleção dos indicadores visando uma adequada catalogação das produções. Posteriormente, com a leitura integral de alguns documentos, ocorreram ajustes ou alterações possibilitando melhor formulação dos descritores.

Assim, foram estabelecidos os seguintes descritores: autor da produção; titulação acadêmica (mestrado, doutorado ou livre-docência); ano de defesa da tese ou dissertação; instituição de ensino superior (IES), unidade acadêmica (UA) e local (região/estado); orientador; graduação do autor; nível escolar: Educação Infantil (EI), Ensino Fundamental (EF, subdividido em EF1, da $1^{\text {a }}$ a $4^{\text {a }}$ séries, e EF2, da $5^{\text {a a }} 8^{\mathrm{a}}$ séries), Ensino Médio (EM), Educação Superior (ES) e Geral (relativo a todos os níveis); foco temático: formação inicial; formação continuada; características, concepções/representações e práticas escolares; elementos teóricos, históricos e curriculares. No caso do foco temático, os trabalhos foram classificados de acordo com o principal foco abordado e, quando havia dois focos com igual relevância, o documento foi classificado em ambos.

A etapa posterior foi identificar as produções existentes na biblioteca da Faculdade de Educação da Unicamp e no Cedoc, para que as demais pudessem ser solicitadas via COMUT (comutação entre bibliotecas) às instituições de ensino nas quais foram defendidas. A obtenção de todos os 65 documentos não foi possível pela não disponibilidade de recursos suficientes para as cópias e pela demora nos processos de solicitação e recebimento via COMUT. As produções não obtidas foram classificadas a partir da leitura dos resumos, procedimento usual em muitas pesquisas do tipo "estado da arte", como em Gamboa (1987) e Ferreira (1999).

A seguir, foram organizadas fichas com a referência da produção e seu resumo, colocadas em ordem alfabética pelo sobrenome do autor e numeradas, servindo ainda como espaço para coleta e registro dos dados levantados a partir da leitura do texto integral ou resumos dos documentos. A partir das classificações pelos descritores escolhidos foram elaboradas 
Formação de professores e educadores...

tabelas de freqüência simples e de cruzamento entre descritores, dados inseridos em planilha do programa Excel visando o tratamento das informações.

\section{Descrição geral das pesquisas}

Em $23(35,4 \%)$ das 65 produções não foi possível identificar a graduação do autor. Nos demais trabalhos, ela constituiu-se por: 11 graduados em Ciências Biológicas (16,9\%), dez em Psicologia (15,4\%), nove em Pedagogia (13,8\%), cinco em Enfermagem (7,7\%), três em Medicina, dois em Filosofia, um em História, um em Bioquímica e um em Letras. Com relação aos orientadores, cinco orientaram dois trabalhos cada um; todos os demais contam com somente uma orientação sobre o tema pesquisado.

Dos documentos, $83,1 \%$ são dissertações de mestrado, 15,4\% teses de doutorado e $1,5 \%$, de livre-docência. A maioria dos mestrados e doutorados foi realizado em Educação (52,3\%). Se a estes somarem-se os da Psicologia da Educação, Educação em Saúde, Educação Pública e os da Educação Especial, o porcentual sobe para aproximadamente 63\%. Seguem-se oito trabalhos defendidos na área da Psicologia, três em Sexologia, dois em Enfermagem, dois na área da Saúde, um em Ensino de Ciências e Matemática e um em Tecnologia Educacional nas Ciências da Saúde. Em sete produções não foi possível obter esse dado.

A primeira produção é uma dissertação de mestrado defendida na Unicamp em 1977 e surge, provavelmente, acompanhando os novos horizontes provenientes da abertura política no país. Após essa data, houve um trabalho defendido em 1982 e outros dois em 1985. Novas defesas só voltam a ocorrer em 1989, quando tornam-se constantes ao longo dos anos, apesar de ainda pouco significativas numericamente.

Na segunda metade dos anos 1990 o número de produções aumenta expressivamente, contando-se com uma média de seis defesas ao ano. Há um pico de produção em 1998 (nove defesas) seguido de um decréscimo em 1999 e uma pequena recuperação no ano posterior. Em 2001, a produção alcança 12 defesas. Os dois últimos anos investigados nesta pesquisa respondem por quase 30\% dos trabalhos. Se for tomado o quadriênio 1998-2001 são encontradas 33 defesas, cerca de $51 \%$ das produções.

As 65 pesquisas são distribuídas por 26 IES, sobressaindo-se a a Universidade de São Paulo (USP) com 13,9\% dos trabalhos, a Universidade Estadual de Campinas (Unicamp), com 12,4\%, seguidas da Pontifícia Universidade Católica do Rio Grande do Sul (Puc-RS) (9,3\%), Pontifícia Universidade Católica de São Paulo (Puc-SP) (7,8\%) e Universidade Federal do Rio Grande do Sul (UFRGS, com 6,3\%). A Universidade Federal de São Carlos (UFSCar), a Universidade Gama Filho (UGF) e a Universidade Estadual Paulista (Unesp) têm três defesas cada uma. As IES que contam com apenas uma dissertação ou tese, à exceção da Universidade do Estado do Rio de Janeiro (UERJ) e da Universidade de Ribeirão Preto (Unaerp), cujos trabalhos foram defendidos em 1991, aparecem apenas a partir de 1997, quando na sociedade aumenta o interesse pela Educação Sexual na escola após a publicação das diretrizes oficiais.

Das instituições de ensino superior, as que contam com teses de doutorado e/ou livre-docência são: a Unicamp e a USP com três trabalhos cada uma; a Puc-RS e a Unesp, com dois; e a Puc-SP com uma produção.

Quanto aos locais de produção, há uma predominância de pesquisas defendidas na 
região sudeste $(61,5 \%)$ e na região sul $(23,1 \%)$, muito provavelmente pela maior concentração de programas de pós-graduação nessas regiões. A seguir aparecem as regiões nordeste $(9,2 \%)$ e centro-oeste $(6,2 \%)$. Não foram identificados trabalhos na região norte do país. O estado que concentra o maior porcentual de produções é São Paulo $(47,7 \%)$, seguido do Rio Grande do Sul $(20,0 \%)$ e do Rio de Janeiro $(10,8 \%)$.

Quanto às unidades acadêmicas, aproximadamente $43 \%$ dos trabalhos foram defendidos em Faculdades/Institutos/Centros e/ou Departamentos de Educação e em torno de 15\% em Faculdades/Centros/Escolas ligados à área da saúde, tais como: Enfermagem, Medicina, Saúde Pública, Psicologia e Ciências da Saúde. Nos demais trabalhos (cerca de 40\%) o dado não pôde ser identificado.

Ao classificar os documentos pelo nível escolar abrangido no trabalho, 11 produções abrangeram dois níveis escolares, sendo classificadas em ambos. Como o porcentual foi calculado sobre o total dos documentos, a soma não corresponde a $100 \%$. O maior porcentual neste descritor coube ao item Geral (35,4\%), ou seja, pesquisas que não são específicas a um nível escolar, incluindo aí as quatro produções realizadas em escolas de portadores de necessidades especiais, uma vez que não explicitavam nenhum nível escolar para o qual se direcionaram.

O Ensino Fundamental, em suas fases e ciclos ou como um todo, é responsável por $41,5 \%$ das produções. No entanto, pouca atenção é dada ao ensino de $1^{a}$ a $4^{a}$ séries $\left(6,2^{\%} \%\right.$ das pesquisas). De $5^{\mathrm{a}}$ a $8^{\mathrm{a}}$ séries aparecem $21,5 \%$ dos trabalhos. Voltados para o Ensino Médio foram identificados 16,9\% e, para a Educação Superior, 12,3\%. Este último nível tem pouca expressividade quantitativa se for considerado que as universidades são responsáveis pela formação inicial dos alunos que posteriormente poderão abordar o tema nos diversos níveis da educação básica.

Os dados obtidos podem sugerir que ainda é incipiente a preocupação com a formação de professores/educadores para o trabalho com Educação Sexual, tanto na educação infantil (10,8\%), quanto no Ensino Fundamental até a $4^{a}$ série. Possivelmente, por serem os alunos da Educação Infantil e das séries iniciais do Ensino Fundamental considerados pelos educadores como de baixa idade para participarem da abordagem do tema.

\section{Descrição e análise dos focos temáticos das pesquisas}

Foram configurados quatro focos temáticos para classificação dos 65 documentos: formação inicial (presente em 6,2\% dos documentos); formação continuada $(27,7 \%)$; características, concepções/representações e práticas escolares (73,8\%); elementos teóricos, históricos e curriculares (10,8\%). A seguir, é apresentado um detalhamento de cada foco e algumas características das pesquisas classificadas em cada um deles. Doze trabalhos $(18,5 \%)$ foram classificados em mais de um foco temático por terem sido abrangidos pela pesquisa com igual relevância.

\section{Foco: Formação inicial}

Neste foco foram inseridas as pesquisas que investigaram a preparação dos futuros professores/educadores e as ações pedagógicas utilizadas nessa formação, seja no Ensino 
Médio (Magistério) ou na Educação Superior (cursos de Licenciatura em Biologia, em Ciências, em Pedagogia, em Enfermagem, entre outros). Também foram incluídas pesquisas sobre a formação de outros profissionais e educadores que acabam, pela própria profissão, podendo abordar o tema nas escolas como, por exemplo, os egressos de cursos de Medicina, de Enfermagem, de Psicologia e de Serviço Social.

Considerando a responsabilidade dos futuros profissionais, é pequena a quantidade de pesquisas identificadas: apenas quatro (6,2\% dos documentos). São produções recentes e o único assunto quantitativamente expressivo é o da DST/AIDS, abordado por duas pesquisas. Em ambas se percebe a compreensão de que a preparação envolve a formação global do educador e não só a aquisição de informações. Quanto à ação pedagógica no processo de formação inicial, são relatadas a utilização de oficinas, sem, no entanto, informar como foram operacionalizadas.

\section{Foco: Formação continuada}

Foram classificadas neste foco as pesquisas que analisaram programas, projetos, cursos, oficinas sobre formação de professores e educadores e as ações pedagógicas utilizadas, além da atuação dos profissionais com temas específicos sobre Educação Sexual enquanto subsídios para sua formação continuada.

Uma síntese das 18 investigações (27,7\%) aqui relacionadas mostra que, de 1977 a 1993, as produções são bastante espaçadas ao longo dos anos e pouco significativas numericamente. Após 1994, as defesas tornam-se freqüentes, com um ou dois trabalhos ao ano, embora não se possa apontar uma tendência contínua ao crescimento das produções. Os trabalhos abrangem principalmente situações voltadas para o Ensino Médio (cinco documentos), para o Ensino Fundamental de $5^{a}$ a $8^{a}$ séries (quatro documentos), prevalecendo no entanto os estudos gerais, não direcionados a um nível escolar específico (seis documentos).

Pela leitura dos documentos foi possível identificar três grandes tendências nos estudos dos autores. A primeira investiga os limites ou dificuldades para a implantação da Educação Sexual nas escolas. A maior evidência é a falta de preparo dos profissionais, cujas causas podem ser atribuídas a vários fatores: pessoais, científicos, institucionais ou oficiais, nesse último caso gerados por políticas públicas insuficientes para garantirem a formação continuada para a abordagem da temática. Como as dissertações e teses desse foco datam dos últimos cinco anos, pode-se considerar que essas limitações estão presentes ainda hoje. As pesquisas revelam ainda que esse despreparo produz condutas discriminatórias e pouco reflexivas, verificadas tanto na postura pessoal quanto profissional, o que colabora para a imposição de valores, mitos e crenças relativos à Educação Sexual. Os autores ressaltam a importância de, na graduação, incluir-se a Educação Sexual na formação dos alunos não só de Pedagogia e de Ciências Biológicas, mas também nos demais cursos de licenciatura, além daqueles que lidam com a área da saúde, como Medicina, Enfermagem, Psicologia e Serviço Social.

A segunda tendência apresenta programas e projetos desenvolvidos em escolas pelo próprio pesquisador ou com sua participação direta objetivando a formação. As experiências relatadas possibilitaram um espaço para o auto-conhecimento nas dimensões pessoal e profissional, a partir de encontros grupais em que o trato das questões da sexualidade aconteciam de forma aberta, dialogal, tendo por base as relações de confiança e troca.

A terceira tendência revela as ações pedagógicas utilizadas na formação, a grande mai- 
oria em processos grupais, mas nem sempre expostas em detalhes no texto da tese ou dissertação. Dentre as ações pedagógicas, a mais significativa numericamente é a oficina (cinco trabalhos), utilizada para sensibilização ou realização de atividades educativas sobre a temática.

Os grupos de discussão/estudo são relatados em quatro produções em que, tanto a dimensão pessoal da sexualidade, quanto a dimensão profissional, foram enfocadas durante um tempo constante e prolongado, possibilitando o desenvolvimento do processo grupal e o aprendizado de saber lidar com as dificuldades. Apontam a reflexão como o principal instrumento utilizado na formação continuada, possibilitando que o processo grupal na formação para o trabalho com Educação Sexual seja o mais eficaz.

Os cursos também aparecem em quatro pesquisas. Todos tiveram por objetivo não só abordar o aspecto informativo, mas também o formativo, provocando mudanças não só no conhecimento, mas também nas atitudes pessoais dos participantes. Com expressão quantitativa menor foram identificadas outras ações pedagógicas: grupo focal (dois trabalhos), em que os autores buscam atingir seus objetivos em poucos encontros, não tendo continuidade processual; assessoria e supervisão (três e dois trabalhos, respectivamente).

\section{Foco: Características, concepções/representações e práticas escolares}

Este foco aglutinou o maior número de pesquisas: 48 (73,8\%), e abrangeu produções que investigaram as concepções/representações dos professores/educadores relativas à sua própria sexualidade ou a aspectos e temas da sexualidade humana ou, ainda, quando abordaram alunos do Ensino Médio ou da Educação Superior enquanto futuros profissionais que poderão trabalhar com o tema. Também foram incluídas nesse foco as pesquisas que apontaram as características necessárias para realizar a abordagem de Educação Sexual, ou que estudaram posturas profissionais e práticas pedagógicas e escolares desenvolvidas na sala de aula ou em outros espaços escolares.

Há uma tendência ao crescimento das pesquisas, principalmente a partir de 1998, sendo que em 2000 e 2001 são encontrados cerca de 23\% dos trabalhos. O nível escolar de maior interesse dos pesquisadores é o Ensino Fundamental, especialmente o período da $5^{\mathrm{a}}$ a $8^{\mathrm{a}}$ séries. O tema das DST/AIDS é o que mais aparece nos trabalhos (nove documentos) seguido da Educação Sexual para deficientes mentais (quatro documentos). Também esse foco foi aglutinado segundo três tendências que estão intrinsecamente relacionadas nas pesquisas.

A primeira investiga as características que devem ter os professores e educadores para trabalharem com Educação Sexual, sendo poucos os trabalhos encontrados. Geralmente são apontadas características subjetivas, ligadas ao gênero feminino: ser boa, compreensiva, séria, mulher ou de qualquer sexo, mãe ou que tenha um equilíbrio mental e psicológico, numa desconsideração com a possibilidade de ambos os sexos abordarem igualmente a temática e numa compreensão subjetiva e discriminatória em relação ao gênero.

A segunda tendência relata posturas e práticas pedagógicas encontradas nas investigações. De maneira geral, essas posturas e práticas, em grande parte, ainda são retrógradas, controladoras e repressoras. Como o tema sexualidade em sala de aula desperta medo, sentimentos de despreparo, vergonha, insegurança e falta de confiança, as ações dos profissionais acabam norteadas pelos valores pessoais dos mesmos, o que está diretamente relacionado aos limites e às dificuldades constatadas nas pesquisas e que contribuem para obstaculizar a implantação da Educação Sexual nas escolas. 
Os professores/educadores encontram dificuldades em trabalhar a partir dos saberes dos alunos, pois os percebem como objetos de suas ações. A preocupação não está em ouvilos, mas em transmitir-lhes informações. Outros profissionais preocupam-se em controlar ou cercear a sexualidade dos educandos. Relatos de posturas indicam que os professores/ educadores não conseguem lidar com a sexualidade infantil, têm dificuldades com o homossexualismo e as relações de gênero e tendem a abordar a Educação Sexual de forma desigual para ambos os sexos, perpetuando com essa prática a discriminação e os estereótipos. Apesar disso, alguns profissionais revelam-se dispostos a manter uma relação de diálogo e confiança com os alunos.

Tais posturas e práticas acabam por levar a uma visão reducionista e simplificadora sobre sexo, privilegiando um enfoque biologicista e higienista, em que predomina o discurso do medo e da doença, sem dar amplitude à questão da sexualidade. Várias pesquisas apontam que os professores/educadores são favoráveis à inclusão da Educação Sexual nos cursos de formação inicial e reconhecem a necessidade de ações e intervenções educativas que lhes possibilite reverem seus conceitos e preconceitos.

$\mathrm{Na}$ terceira tendência encontra-se a maioria das pesquisas desse foco temático e referem-se às concepções/representações dos profissionais. Relatos mostram que, de maneira geral, estas se encontram ao nível do senso comum, perpetuando valores, conceitos e preconceitos e com uma representação da sexualidade humana atrelada ao sexo orgânico. Os pesquisadores observam uma negação da sexualidade infantil nas concepções/representações dos profissionais, pois alguns consideram as crianças de faixas escolares mais baixas como pequenas, ingênuas e assexuadas, das quais as questões sexuais devem ser ocultadas. Como a imagem da aids é incompatível com essa imagem da criança, esta é desprivilegiada nas ações de prevenção da doença.

As pesquisas mostram ainda que a escola é concebida pelos profissionais como conservadora, repressora, sem abertura para ver, ouvir e compreender os educandos, não dando visibilidade à temática, e perpetuando mecanismos repetitivos e controladores que poriam em risco a abordagem adequada da Educação Sexual. A família é percebida como não preparada para a mesma e, por isso, precisa ser envolvida no processo.

Também nessa terceira tendência, localizam-se os profissionais que têm concepções diferentes em relação à Educação Sexual: uns acham que ela deve começar assim que a criança entra na escola e ser trabalhada como algo normal na vida; outros consideram que meninos e meninas devem receber a mesma Educação Sexual, porém, separadamente. Os profissionais parecem não ter uma concepção integrada da sexualidade, pois muitas vezes ela se encontra desvinculada de aspectos afetivos. Priorizam temas como gravidez e prevenção em DST/ AIDS com enfoque na relação saúde/doença, numa concepção biologicista.

Vale destacar que quatro documentos tratam do tema em relação aos deficientes mentais, reconhecendo a necessidade da Educação Sexual para estes. Contudo, tanto a escola como os professores e educadores percebem os alunos desse grupo que demonstram mais intensamente manifestações sexuais como agressivos, com sensibilidade exacerbada e com um nível maior de desvio e defeitos de caráter, levando a escola a considerá-los como problemáticos. Alguns profissionais concebem os deficientes como incapazes de entender e/ou sentir necessidades sexuais em razão da infantilidade originada da deficiência; outros lhes vetam o direito a casar e ter filhos. Autores afirmam a necessidade de serem trabalhados não só os 
profissionais, mas também a família, para que haja continuidade no processo de educação.

\section{Foco: Elementos teóricos, históricos e curriculares}

O quarto foco temático contou com sete produções (10,8\%). Foram incluídos ensaios e outras formas de produção científica que investigaram concepções teórico-filosóficas e suas contribuições para a fundamentação de programas/projetos de Educação Sexual; pesquisas que analisaram currículos a partir da existência de disciplinas que enfocam a sexualidade ou que dirigiram seus estudos para a Educação Sexual nos PCNs; e, ainda, estudos que historicizaram a sexualidade humana e o processo da Educação Sexual. Especialmente nesse foco, foram apontados subsídios teóricos e metodológicos para programas de formação inicial e continuada.

Há dois estudos sobre análises de currículos de faculdades: um em cursos de Biologia e outro em cursos de Medicina. Os estudos indicam que as ementas das disciplinas tratam o tema de modo restrito às explicações biológicas e mecânicas das características anatômicas, fisiológicas e patológicas. Uma pesquisa verificou a aplicação da proposta de Orientação Sexual dos PCNs (dificuldades e principais avanços) e duas realizaram estudos teóricos-críticos sobre a relação entre Filosofia, Educação e Educação Sexual. Quanto às demais produções, uma pesquisou as orientações curriculares oficiais de São Paulo através dos cursos da Coordenadoria de Estudos e Normas Pedagógicas - CENP, da Secretaria de Estado da Educação, apresentando pressupostos teóricos para a Educação Sexual; e a outra fez um ensaio crítico sobre o tema, com indicativos para a realização do processo de formação de profissionais.

\section{Considerações finais}

Da análise das pesquisas de pós-graduação sobre a formação do professor/educador para abordagem da Educação Sexual nas escolas defendidas no período de 1977 a 2001, algumas considerações merecem ser destacadas.

As pesquisas referentes ao ensino de $1^{\text {a }}$ a $4^{\text {a }}$ séries são as menos expressivas quantitativamente (em torno de 6\%), mas também são poucas as investigações na Educação Infantil (cerca de 11\%). Se for considerada a faixa etária de zero a dez anos, é possível compreender o pouco interesse pela produção de trabalhos na área, uma vez que a representação dos professores concebe estes alunos como inocentes, puros, assexuados... não carecendo, portanto, da abordagem com a temática. No entanto, é nas idades mais precoces que mais facilmente são absorvidos valores, conceitos e preconceitos, sendo fundamental a intensificação das pesquisas nas séries iniciais de escolarização e na educação infantil.

Carecem de maior investimento as pesquisas na Educação Superior, também pouco expressivas quantitativamente (em torno de $12 \%$ ), perante a importância na qualificação de futuros profissionais e também pela participação de docentes da universidade na formação continuada e no desenvolvimento de programas em nível de extensão e de especialização.

O Ensino Médio, referente aos cursos de habilitação ao Magistério e aos cursos técnicos na área da Saúde, ainda precisa de mais investigações, pois este é o momento da sensibilização e formação dos futuros profissionais para atuação com tal abordagem. Além disso, possibilitaria a eles se tornarem multiplicadores de conceitos e valores na Educação Sexual 
ligados à conquista dos direitos humanos e da cidadania.

Há necessidade de maior sensibilização dos professores/educadores para que se disponham à abordagem com Educação Sexual, uma vez que as características apontadas nos documentos são bastante idealizadas nos seus aspectos subjetivos (ser séria, boa, compreensiva, amiga, ter equilíbrio/amadurecimento mental e psicológico) e altamente exigentes nos objetivos (estar preparado/ter conhecimento do assunto, ter interesse em desenvolvê-lo e não passar seus valores). Como por esse perfil idealizado os profissionais sentem-se distantes de grande parte dessas características, acabam não realizando e, mesmo, distanciando-se da abordagem do tema.

Sem uma formação inicial e continuada eficiente e eficaz os resultados apontados sobre as posturas e práticas escolares na abordagem da Educação Sexual continuarão, em grande parte, tais como se apresentam nas pesquisas. Em face de suas dificuldades, o professor/educador acha melhor tratar dos aspectos biológicos pura e simplesmente e, para isso, considera que "existe o professor da área de Ciências". Então, "Educação Sexual nada tem a ver comigo", o que o tranqüiliza em relação a seu falso "não-envolvimento" com o tema. É preciso, principalmente na formação continuada, resgatar o élan vital, a energia que vai possibilitar ao professor/educador a recuperação do prazer com a profissão escolhida.

O despreparo dos profissionais nas diversas produções identificadas precisa ser reconhecido e enfrentado pelos sistemas públicos educacionais se estes esperam que muitas das orientações sobre o tema, contidas especialmente nos Parâmetros Curriculares Nacionais, não fiquem reduzidas a orientações técnicas sem implementação na prática escolar. O mérito dos PCNs foi possibilitar a abordagem da Educação Sexual sem a perspectiva de proibição e repressão antes dominantes, mas sua grande lacuna está em não garantir o espaço coletivo reflexivo e continuado da formação do professor/educador para o trabalho com Educação Sexual, que possibilite a interação entre o pessoal e o profissional. Se já é difícil que o professor de Ciências Biológicas assuma o trabalho com a Educação Sexual em todas as suas dimensões, o que dizer em relação aos professores de áreas diferentes, por exemplo, professores de Matemática, Física ou Geografia, distantes desta temática na sua formação inicial?

A formação continuada passa também pela necessidade de maior número de pesquisas e formação dos diversos profissionais que atuam no espaço escolar, desde a direção, os assistentes, os supervisores, mas, também, as secretárias, as serventes, as merendeiras que também precisam ser investigados enquanto educadores.

Várias dissertações e teses referem a importância de a universidade assumir a formação dos profissionais ao lado dos programas oficiais. Para tal, é necessário, entre outros fatores, a sensibilização e a preparação dos docentes da Educação Superior, que também não foram formados para o trabalho com a temática. Mais ainda, a formação inicial é prioritária (exatamente a que conta com menos pesquisas no conjunto das 65 produções), pois é preciso assegurar que os profissionais já saiam de seus cursos preparados para tal abordagem. Assim, a inclusão da Educação Sexual nos cursos de graduação é fundamental.

A partir das considerações formuladas e para que se possa iniciar a superação dos problemas apontados nas diversas pesquisas, faz-se necessária a atenção a alguns aspectos.

O reconhecimento pelo poder público da necessidade de abordagem da sexualidade é recente na educação formal. Isto remete à observação de que o processo de revisão das posturas e condutas adotadas histórica e culturalmente por professores e educadores não se efetiva- 
Silva, R. C. P; Megid Neto, J.

rá num período curto. Dependerá, essencialmente, da possibilidade de reflexão e diálogo com os mesmos e da abertura de espaço grupal para que isto ocorra na escola. Como a proposta desta abordagem nos PCNs não é obrigatória, faz-se necessária a sensibilização dos gestores e professores, em todos os níveis de ensino, para que ela aconteça. E, ainda, a atenção para o fato de que treinamentos e palestras, por si sós, não são suficientes para garantir o objetivo que se quer alcançar: profissionais sensíveis ao tema e dispostos a essa abordagem de maneira sistemática, uma vez que as experiências mostram que a maioria das dúvidas e das inseguranças só aparece na ação, o que remete à necessidade de supervisão continuada e sistemática.

Por outro lado, as instituições de ensino superior, em seus cursos de habilitação ao magistério e nos cursos ligados à temática, como Enfermagem, Fisioterapia, Medicina, Psicologia, Serviço Social, dentre outros, além dos cursos de Ensino Médio da área da Saúde, devem ser sensibilizadas para o tema e incluir a Educação Sexual em seus currículos, visando a formar profissionais já preparados para essa abordagem. Se essas instituições forem sensibilizadas pelos profissionais que já vêm trabalhando com o tema será possível um grande avanço na superação desta lacuna na educação formal.

\section{Referências}

BAGNATO, M. H. S. A contribuição educativa dos programas de saúde na $5^{\mathrm{a}}$ série do $1^{\circ}$ grau. São Paulo. 1987. 148f. Dissertação (Mestrado em Educação) - Centro de Educação e Ciências Humanas, UFSCar.

BAPTISTA, D. M. T. O debate sobre o uso de técnicas qualitativas e quantitativas de pesquisa. In: MARTINELLI, M. L. (Org.). Pesquisa qualitativa: um instigante desafio. São Paulo: Veras, 1999.

BRASIL. Ministério da Educação e do Desporto. Parâmetros Curriculares Nacionais $\left(3^{\circ} \mathrm{e}\right.$ $4^{\circ}$ ciclos): introdução aos parâmetros curriculares nacionais. Brasília, 1998.

FERREIRA, N. S. A. Pesquisa em leitura: um estudo dos resumos de dissertações de mestrado e teses de doutorado defendidas no Brasil, de 1980 a 1995. São Paulo. 1999. Tese (Doutorado em Educação) - Faculdade de Educação, Unicamp.

FIGUEIRÓ, M. N. D. Educação Sexual no Brasil: estado da arte de 1980-1993. São Paulo. 1995. 272f. Dissertação (Mestrado em Psicologia) - Instituto de Psicologia, USP.

FRACALANZA, H. O que sabemos para livros didáticos para o ensino de Ciências no Brasil. São Paulo. 1993. 241f. + anexos. Tese (Doutorado em Educação) - Faculdade de Educação, Unicamp.

FRUET, M. S. B. Adolescência, sexualidade e aids. São Paulo. 1995. 125f. Dissertação 
Formação de professores e educadores...

(Mestrado em Educação) - Faculdade de Educação, Unicamp.

GAMBOA, S. A. S. Epistemologia da pesquisa em educação: estruturas lógicas e tendências metodológicas. São Paulo. 1987. 228f. Tese (Doutorado em Educação) - Faculdade de Educação, Unicamp.

LÜDKE, M. Pesquisa em educação: conceitos, políticas e práticas. In: GERALDI, C. M. G.; FIORENTINI, D.; PEREIRA, E. M. A. (Orgs.). Cartografias do trabalho docente: professor(a)-pesquisador(a). Campinas: Mercado de Letras: Associação de Leitura do Brasil, 2000. p. 23-32.

MEGID NETO, J. (Org.). O ensino de Ciências no Brasil: catálogo analítico de teses e dissertações 1972-1995. Campinas: Faculdade de Educação/Cedoc, Unicamp, 1998.

Tendências da pesquisa acadêmica sobre o ensino de Ciências no nível fundamental. São Paulo. 1999. 114f. Tese (Doutorado em Educação) - Faculdade de Educação, Unicamp.

RIBEIRO, P. R. M. Uma contribuição ao estudo da sexualidade humana e da educação sexual. São Paulo. 1989. 107f. Dissertação (Mestrado em Educação) - Faculdade de Educação, Unicamp.

SAYÃO, Y. Orientação sexual na escola: os territórios possíveis e necessários. In: AQUINO, J. G. (Org.). Sexualidade na escola: alternativas teóricas e práticas. São Paulo: Summus, 1997. p. 107-117.

SCHIAVO, M. R.; SILVA, M. do C. de A. Educação Sexual: história, conceitos \& metodologia. In: SILVA, M. do C. de A.; SERAPIÃO, J. J.; JURBERG, P. Sexologia: interdisciplinaridade nos modelos clínicos, educacionais e na pesquisa. Rio de Janeiro: Universidade Gama Filho, 1997. p. 149-189.

SCHUSSEL, D. R.. Educação Sexual: análise de opiniões de diferentes segmentos sociais. São Paulo. 1982. 114f. Dissertação (Mestrado em Educação), PUC-SP.

VERARDO, M. T. V. A sexualidade educada: nota crítica sobre pressupostos teóricos e projetos empíricos. São Paulo. 1989. 140f. Dissertação (Mestrado em Educação) - Faculdade de Educação, Unicamp. 